\title{
Laboratory Experiments on Enhanced Oil Recovery with Nitrogen Injection
}

\author{
S. Siregar, A. D. Hidayaturobbi, B. A. Wijaya, S.N. Listiani, T. Adiningrum, Irwan \\ \& A.I. Pratomo
}

Faculty of Mining and Petroleum Engineering, Bandung Institute of Technology

\begin{abstract}
Based on previous studies, nitrogen injection could recover oil up to $45-90 \%$ of initial reserves. Although this method has a very good ability to produce oil, sometimes the operation pressure is higher than leak off formation pressure. In this study, operation pressure used a low pressure to solve this problem under immiscible process. Objective of this study is to determine the effect of injection pressure and displacement rate on oil recovery performance of continuous one dimensional nitrogen gas injection with a slim tube apparatus. The effect of nitrogen gas-oil contact on the gas composition was investigated using Gas Chromatograph Mass Spectrometer apparatus. In the experiments, nitrogen gas was injected into an oil sample of $38.5^{\circ} \mathrm{API}$ gravity at various rates: $20 \mathrm{cc} / \mathrm{hr}, 30 \mathrm{cc} / \mathrm{hr}$ and 36.66/hr under $1500 \mathrm{psi}$ pressure, and then at $20 \mathrm{cc} / \mathrm{hr}$ undr $2500 \mathrm{psi}$ pressure. The results showed that an increase in injection rate increased oil recovery factor. The recovery factor lies between $40-54 \%$ of original oil in place. Gas analysis before injection and at the injection outlet showed a change of composition. when oil was contacted by nitrogen, indicating that some molecular mass transfer had taken place.
\end{abstract}

Keywords: nitrogen injection; immiscible process; molecular mass transfer.

\section{$1 \quad$ Introduction}

In the year 1970's, enhanced oil recovery (EOR) became a popular and important technique in the petroleum industry. The declining of oil production and languid of new oil reserves combined with the rising demand for oil, had become a reason for EOR techniques to develop. Furthermore the high demand for oil and gas, which was not equalized by the production, made a significant rising in oil and gas prices. Now, EOR techniques become one of the top priorities for technology development in petroleum industry [1].

EOR method consists of secondary and tertiary recovery. Those methods are used for increasing hydrocarbon recovery from the reservoir with changing fluid characteristics sometimes even changing reservoir characteristics. There are two classical secondary recovery methods that we still use today. These methods are water injection and gas injection that have proven to increase oil and gas recovery.

Received May 29 2006. 
Other gases may be used for increasing oil and gas recovery such as lean gas, $\mathrm{CO}_{2}$, fuel gas, air, and nitrogen. Nitrogen has dated back to fifty years to have an important role in the petroleum industry, such as in well completion and well work over [2] to [11]. There are some advantages when using nitrogen injection in the field:

- Nitrogen is not corrosive to field equipment.

- Nitrogen gas is relatively inexpensive than other injection gas (e.g. lean gas).

- Nitrogen can be produced in the field with particular separation equipment by extracting nitrogen from the air.

- Nitrogen is harmless compared to other gas (not flammable).

The objective of this research is to investigate the effects of injection pressure and displacement rate to reservoir recovery. The parameters which investigated were oil recovery and composition of nitrogen gas before and after injection.

\section{Laboratory Experiments}

Slim tube apparatus and sample tubes, which are used in this research, deliver production behavior when an oil sample in the slim tube is injected with nitrogen gas. The displacement that occurs in slim tube apparatus is one dimensional displacement. Alterations in oil physical properties were investigated. Under this condition, oil sample will have a direct contact with nitrogen gas. Those instruments are facilities of the EOR laboratory of the Petroleum Engineering Department, Institut Teknologi Bandung (ITB), where the research has been performed. The last apparatus used is gas chromatography mass spectrometry (CGMS). This tool was used for identifying the composition of nitrogen gas before and after the experiment using Slim Tube Apparatus, which is a facility of the Chemical Engineering Department ITB.

The experiments used one oil sample under the injection pressures of 1500 and 2500 psig. Each run was operated at various injection rates to identify an optimum injection rate which gives the maximum oil recovery [12]. The slim tube characteristics and research conditions applied during these experiments are given in Tables 1 and 2.

Table 1 Data properties.

\begin{tabular}{ll}
\hline Reservoir pressure (psig) & 1200 \\
API gravity $\left({ }^{0}\right)$ & 38.5 \\
Oil viscosity $(\mathrm{cp})$ & 1.06 \\
\hline
\end{tabular}


Table 2 Slim tube characteristics.

\begin{tabular}{cc}
\hline Parameter & Remarks \\
\hline Length & 13 meters \\
OD & $0.8 \mathrm{~cm}$ \\
ID & $0.535 \mathrm{~cm}$ \\
Porosity & $35-42 \%$ \\
Permeability & 5 Darcy \\
Sand & Ottawa Sand \\
\hline
\end{tabular}

Equipments that are used in this research are slim tube apparatus, gas chromatography-mass spectrometry (GCMS), mercury pump, hydrometer, syringe. The image of slim tube apparatus can be seen in Figure 1. Materials that are used in this research are oil sample of KAJI Field, nitrogen gas, toluene, and mercury.
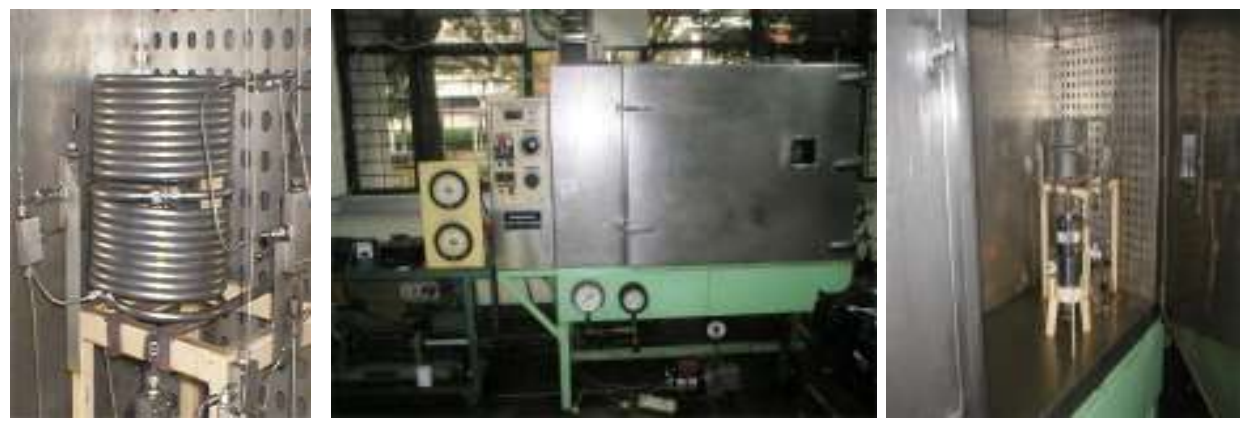

Figure 1 Slim tube apparatus (manufactured at Robinson Inc., Canada. Details are given in Table 2. The jacket was manufactured at ITB).

\section{$3 \quad$ Analysis \& Evaluation}

Based on four following experiments, we found that oil recovery increases with injection rate. A plot between $\mathrm{N}_{2}$ injected (in pore volume) and recovery factor can be seen in Figure 1 (for $P_{i}=1500$ psig and $q_{i}=20 \mathrm{cc} /$ hour), Figure 2 (for $P_{i}$ $=1500 \mathrm{psig}$ and $\mathrm{q}_{\mathrm{i}}=20 \mathrm{cc} /$ hour ), Figure 3 (for $\mathrm{P}_{\mathrm{i}}=1500 \mathrm{psig}$ and $\mathrm{q}_{\mathrm{i}}=36.66$ $\mathrm{cc} /$ hour), and Figure 4 (for $\mathrm{P}_{\mathrm{i}}=2500 \mathrm{psig}$ and $\mathrm{q}_{\mathrm{i}}=20 \mathrm{cc} /$ hour). Comparison of injection process can be seen in Table 3 , where it is shown that higher injection rates result in higher recovery factor. This is probably due to a more stable nitrogen front which is formed behind the oil bank. It was observed that there was an increase recovery factor from $P_{i}=1500$ psig and $q_{i}=20 \mathrm{cc} /$ hour to $P_{i}=$ 
1500 psig and $\mathrm{q}_{\mathrm{i}}=30 \mathrm{cc} /$ hour. However, at $\mathrm{P}_{\mathrm{i}}=1500$ psig and $\mathrm{q}_{\mathrm{i}}=36.66$ $\mathrm{cc} /$ hour the recovery factor decreased. It indicates that there is an optimum injection rate for nitrogen injection. Hence higher injection rate does not always increase the recovery factor.

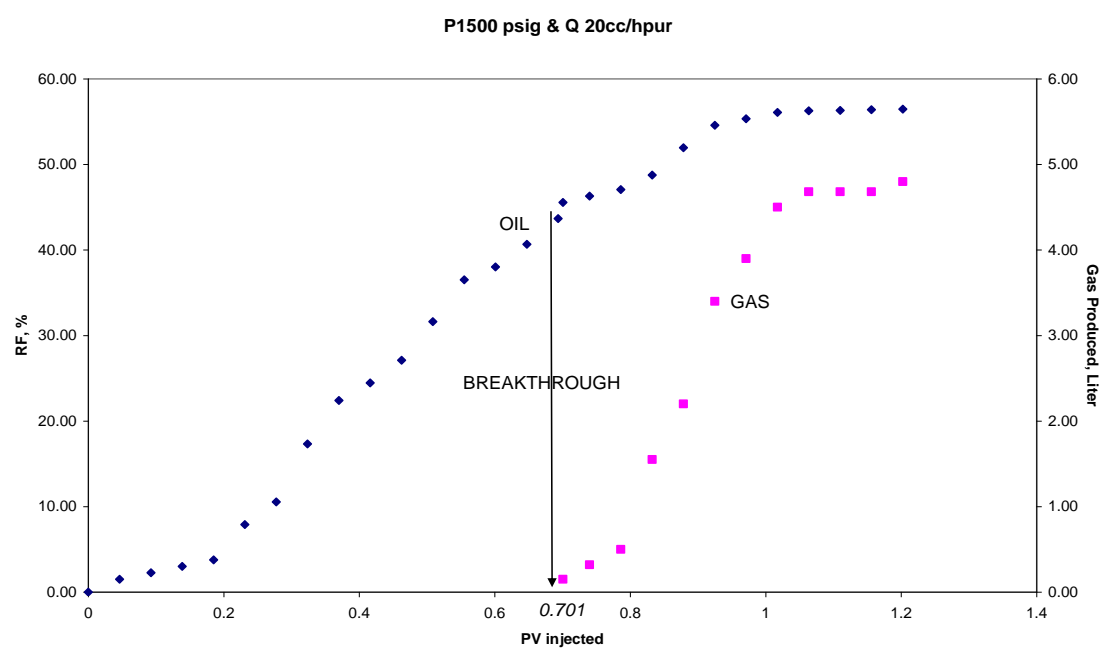

Figure 2 Relationship between recovery factor and pore volume injected at injection pressure $\left(\mathrm{P}_{\mathrm{i}}\right)=1500 \mathrm{psig}$ and injection rate $\left(\mathrm{q}_{\mathrm{i}}\right)=20 \mathrm{cc} /$ hour.

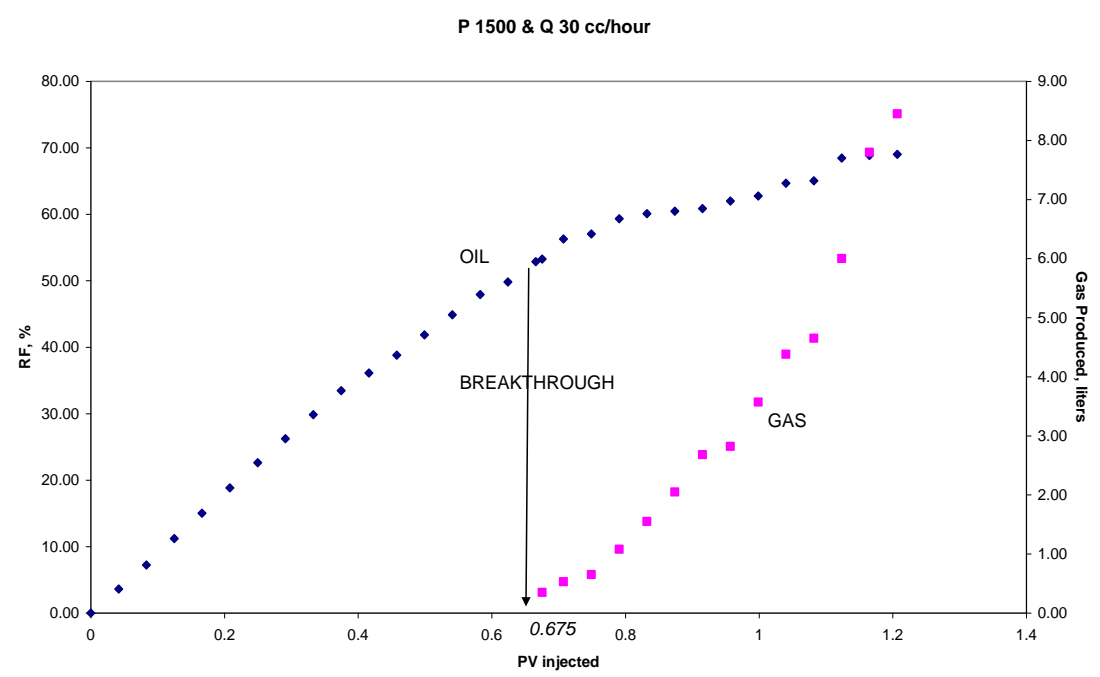

Figure 3 Relationship between recovery factor and pore volume injected at injection pressure $\left(\mathrm{P}_{\mathrm{i}}\right)=1500$ psig and injection rate $\left(\mathrm{q}_{\mathrm{i}}\right)=30 \mathrm{cc} /$ hour. 
On the other hand, we found that there was an increase in recovery factor when conducting the experiment by operating the greater injection pressure with constant injection rate. The results for experiments at $\mathrm{P}_{\mathrm{i}}=1500$ psig \& $\mathrm{q}_{\mathrm{i}}=$ $20.00 \mathrm{cc} /$ hour and $\mathrm{P}_{\mathrm{i}}=2500 \mathrm{psig} \& \mathrm{q}_{\mathrm{i}}=20 \mathrm{cc} /$ hour show a decreasing recovery. It was caused by early breakthrough shown by the $0.43 \mathrm{PVI}$, which is much lower than an ideal piston-like displacement process breakthrough time of 1 PVI.

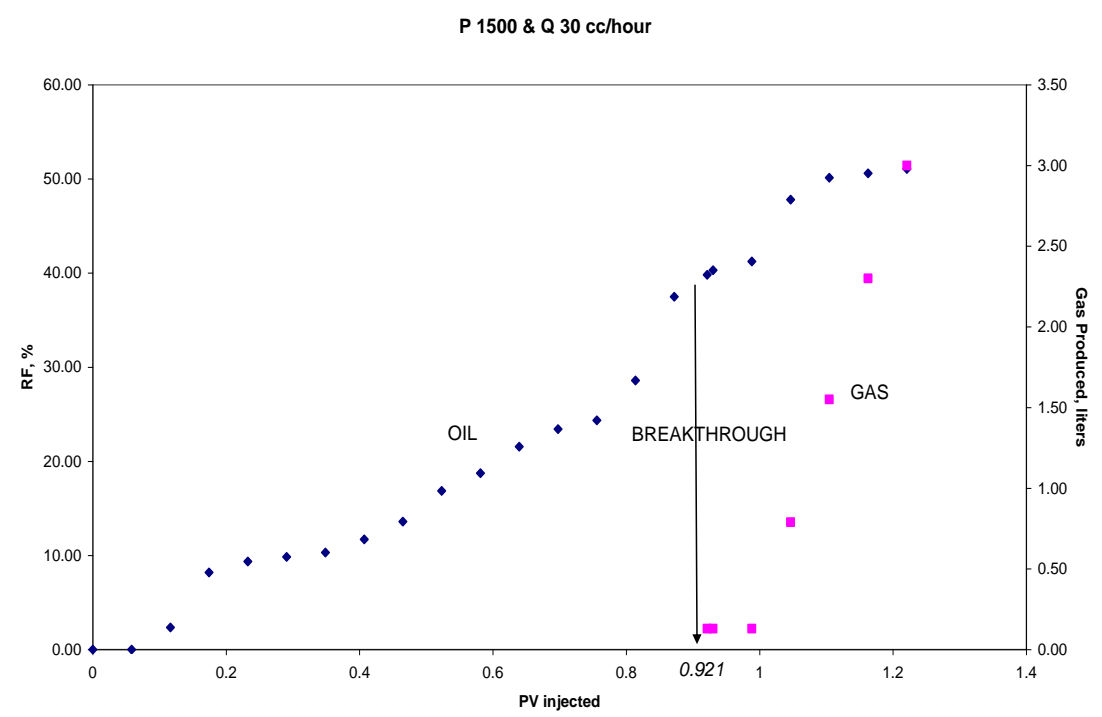

Figure 4 Relationship between recovery factor and pore volume injected at injection pressure $\left(\mathrm{P}_{\mathrm{i}}\right)=1500 \mathrm{psig}$ and injection rate $\left(\mathrm{q}_{\mathrm{i}}\right)=36.66 \mathrm{cc} /$ hour.

Table 3 Data properties at various injection rates and pressures.

\begin{tabular}{ccccc}
\hline Parameters & $\begin{array}{c}\mathbf{P}_{\mathbf{i}}=\mathbf{1 5 0 0} \mathbf{~ p s i g} \\
\mathbf{q}_{\mathbf{i}}=\mathbf{2 0} \mathbf{c c} / \mathbf{h o u r}\end{array}$ & $\begin{array}{c}\mathbf{P}_{\mathbf{i}}=\mathbf{1 5 0 0} \mathbf{~ p s i g} \\
\mathbf{q}_{\mathbf{i}}=\mathbf{3 0} \mathbf{c c} / \mathbf{h o u r}\end{array}$ & $\begin{array}{c}\mathbf{P}_{\mathbf{i n j}}=\mathbf{1 5 0 0} \mathbf{~ p s i g} \\
\mathbf{q}_{\mathbf{i}}=\mathbf{3 6 . 6 6} \mathbf{c c} / \mathbf{h o u r}\end{array}$ & $\begin{array}{c}\mathbf{P}_{\mathbf{i}}=\mathbf{2 5 0 0} \mathbf{~ p s i g} \\
\mathbf{q}_{\mathbf{i}}=\mathbf{2 0} \mathbf{c c} / \mathbf{h o u r}\end{array}$ \\
\hline Vo initial & $108.12 \mathrm{cc}$ & $120.16 \mathrm{cc}$ & $86.010 \mathrm{cc}$ & $102.160 \mathrm{cc}$ \\
RF@BT & $51.144 \%$ & $53.246 \%$ & $39.827 \%$ & $43.823 \%$ \\
Oil prod@BT & $55.297 \mathrm{cc}$ & $63.98 \mathrm{cc}$ & $34.255 \mathrm{cc}$ & $44.770 \mathrm{cc}$ \\
PV inj@BT & 0.701 & 0.675 & 0.921 & 0.430 \\
RF after 1.2 PV & $\mathbf{6 3 . 4 0 2 \%}$ & $\mathbf{6 9 . 0 2 9} \%$ & $\mathbf{5 1 . 0 7 2} \%$ & $\mathbf{6 0 . 1 5 8 \%} \%$ \\
Total oil prod & $68.550 \mathrm{cc}$ & $82.946 \mathrm{cc}$ & $43.927 \mathrm{cc}$ & $61.457 \mathrm{cc}$ \\
$\begin{array}{c}\text { Blowdown } \\
\text { Recovery }\end{array}$ & $16 \mathrm{cc}$ & $10.2 \mathrm{cc}$ & $9 \mathrm{cc}$ & $5 \mathrm{cc}$ \\
\hline
\end{tabular}




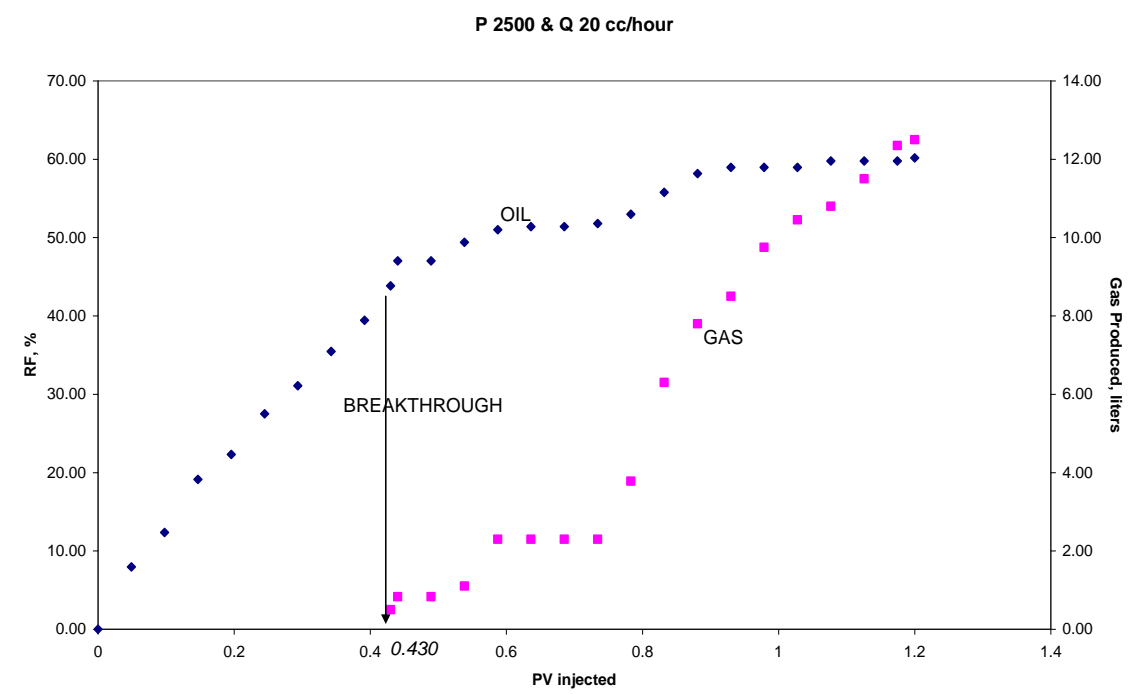

Figure 5 Relationship between recovery factor and pore volume injected at injection pressure $\left(\mathrm{P}_{\mathrm{i}}\right)=2500$ psig and injection rate $\left(\mathrm{q}_{\mathrm{i}}\right)=20 \mathrm{cc} /$ hour.

Table 4 Gas concentration before and after injection.

\begin{tabular}{cccccc}
\hline Component & $\begin{array}{c}\text { Before } \\
\text { Injection }\end{array}$ & $\begin{array}{c}\mathbf{P}_{\mathbf{i}}=\mathbf{1 5 0 0} \mathbf{~ p s i g} \\
\mathbf{q}_{\mathbf{i}}=\mathbf{2 0} \text { cc/hour }\end{array}$ & $\begin{array}{c}\mathbf{P}_{\mathbf{i}}=\mathbf{1 5 0 0} \mathbf{p s i g} \\
\mathbf{q}_{\mathbf{i}}=\mathbf{3 0} \text { cc/hour }\end{array}$ & $\begin{array}{c}\mathbf{P}_{\mathbf{i}}=\mathbf{1 5 0 0} \mathbf{p s i g} \\
\mathbf{q}_{\mathbf{i}}=\mathbf{3 6 . 6 6} \text { cc/hour }\end{array}$ & $\begin{array}{c}\mathbf{P}_{\mathrm{i}}=\mathbf{2 5 0 0} \mathbf{~ p s i g} \\
\mathbf{q}_{\mathbf{i}}=\mathbf{2 0} \text { cc/hour }\end{array}$ \\
\hline $\mathbf{N}_{\mathbf{2}}$ & $99.336 \%$ & $80.803 \%$ & $85.60 \%$ & $78.468 \%$ & $79.1617 \%$ \\
$\mathbf{O}_{\mathbf{2}}$ & $0.6639 \%$ & $18.745 \%$ & $13.872 \%$ & $19.6811 \%$ & $13.9296 \%$ \\
$\mathbf{C O}_{\mathbf{2}}$ & $0 \%$ & $0.451 \%$ & $0.5216 \%$ & $1.8508 \%$ & $6.9086 \%$ \\
Total & $\mathbf{1 0 0 \%}$ & $\mathbf{1 0 0 \%}$ & $\mathbf{1 0 0 \%}$ & $\mathbf{1 0 0 \%}$ & $\mathbf{1 0 0 \%}$ \\
\hline
\end{tabular}

Based on the analysis on gas chromatography - mass spectrometry (GCMS), we perceived that gas which was taken from slim tube outlet has different concentrations of nitrogen and oxygen than before the injection process. The change in gas concentrations can be seen in Table 4, where there was an increase of oxygen and carbon dioxide concentration after the injection. This is caused by the molecular mass transfer between nitrogen gas and oil, where oil has oxygen and carbon as its components. Thus oxygen and carbon dioxide gases are released from the oil and entered the gas stream joining the nitrogen. At the higher injection rate of $30 \mathrm{cc} /$ hour, oxygen free gas percentage was less, probably due to oxidation process taking place, which consumed oxygen in the oil during injection. This oxidation helped increase the oil recovery. However, at higher injection rate of $36.66 \mathrm{cc} /$ hour, the flow rate might have been too high for an effective oxidation process to take place, so there was more oxygen 
released as free gas. This probably caused fingering or early breakthrough which resulted in the observed lower oil recovery.

\section{Conclusions}

1. Increasing injection rate did not always increase recovery factor, but there was an optimum injection rate for nitrogen injection.

2. There was a difference in gas composition before and after injection process, indicating that some molecular transfer has taken place even at pressures below the miscibility pressure.

\section{Acknowledgement}

This research was funded by ITB Research Grant no. 0076/K01.03/PL2.1.5/VI/2005.

\section{References}

[1] Willhite, G. P. \& Green, D. W., Enhanced Oil Recovery, Textbook Series, SPE Richardson, Texas, 1998.

[2] Vogel, J.L. \& Yarbourough, L., The Effect of Nitrogen On The Phase Behavior and Physical Properties of Reservoir Fluids, SPE 8815, 1980.

[3] Slack, W. W. \& Ehrlich, R., Immiscible Displacement of Oil By Simultaneous Injection of Water and Nitrogen, SPE 9807, 1981.

[4] Clancy, J. P., Gilchrist, R. E., \& Kroll, D.E., Nitrogen for Enhanched of Oil and Gas, SPE 9912, 1981.

[5] Alcocer, C.F., Mezie, D. \& Crichlow, H., Preliminary Experimental Results of High Pressure Nitrogen Injection for EOR system, SPE, 1983.

[6] Adler, A. B. \& Crawford, P. B., Nitrogen Injection into Water-Driven Natural Gas or Condensate Reservoirs Increase Recovery, SPE 12046, 1983.

[7] Ypma, J.G.J., Compositional Effects in Gravity-Dominated Nitrogen Displacement, SPE 14416, 1988.

[8] Glaso, G., Miscible Displacement: Recovery Tests with Nitrogen, SPE 17378, 1990.

[9] Sebastian, H.M. \& Lawrence, D.D., Nitrogen Minimum Miscibility Pressure, SPE 24134, 1992.

[10] Evison, B. \& Gilchrist, R. E., New Development in Nitrogen in the Oil Industry, SPE 24313, 1992.

[11] Mungan, N., High Pressure Nitrogen Injection For Miscible/Immiscible Enhanced Oil Recovery, SPE 81008, 2003.

[12] Tjahjono, W., Penentuan Harga Tekanan Tercampur Minimum (TTM) Pada Pendesakan Minyak Oleh $\mathrm{CO}_{2}$ dan Penelitian Awal Pengaruh 
Komposisi Minyak, Temperatur dan Berat Molekul Pada TTM Dengan Menggunakan Peralatan Slim Tube, Thesis, ITB, 1992. 